\title{
Generation Capacity Investment in oligopolistic Electricity Markets under Uncertainty
}

\author{
Anton Burger* Robert Ferstl ${ }^{\dagger}$
}

\section{Overview}

The paper discusses game theoretic models for generation capacity investment decisions in a deregulated electricity market. We present an example of an S-adapted Cournot equilibrium, which we apply to the German electricity market. Investment decisions derived by this dynamic oligopoly model are then compared to what the perfect competition result in an otherwise unchanged setup would be. The contribution of this paper is that it extends the work of Genc et al. (2007) and Genc and Sen (2008) in two important directions. First, we take the model to a more detailed level by using all available technologies and a realistic approximation of the load duration curve. The second, and more important contribution is that we establish a competitive benchmark and link the model to economic theory to answer the normative question whether such an oligopolistic investment game under uncertainty leads to an optimal level of investments and an optimal technology mix. We conclude that there seems to be a problem with underinvestment and technology mix in the current market structure.

\section{Methods}

We model an oligopolistic investment game with four players (RWE, EON, Vattenfall and EnBW), seven technologies and six different states in which the market might be (very high price, low price...). The two deciding factors are first dynamics and thereby investments which link the different time periods and second, uncertainty which is accounted for by a binomial scenario tree and leads to a recourse problem. The uncertainty about future demand is accounted for by different demand scenarios. Each player maximizes its profit by setting quantities and Investments. By considering different demand developments and the associated probabilities of the different scenarios, the players take into account how demand might evolve in the future. Quantities are allowed to be adapted to different scenarios that evolve, thereby accounting for the fact that firms can always react to demand by adjusting the short run production. On the contrary, investments are not allowed to differ in such a way as they

\footnotetext{
*Institute for Regulatory Economics, Vienna University of Economics and Business Administration, anton.burger@wu-wien.ac.at

${ }^{\dagger}$ Department of Finance, University of Regensburg, robert.ferstl@wiwi.uni-regensburg.de
} 
Table 1: Investments in different market forms, with and without availability of B. Coal sites (MW)

\begin{tabular}{|c|c|c|c|c|}
\hline \multicolumn{3}{|l|}{ investments } & \multicolumn{2}{|c|}{ Scen. w. Brown Coal } \\
\hline oligopoly & & Brown Coal & Nuclear & Hard Coal \\
\hline & EON & 1063 & & \\
\hline & Vatten & 7256 & 6249 & 283 \\
\hline & EnBW & 9102 & 8248 & \\
\hline & Sum & 17422 & & 4780 \\
\hline optimum & & 31096 & 27658 & \\
\hline
\end{tabular}

source: own calculations

have to be set in advance when it is not clear jet how high demand might be. If quantities would depend on Investments of other players as well, we would enter the realm of feedback or closed loop games. It has to be noted here that the solution of a closed loop game can, and will, in general, be different from the solution of an open loop game.

The state equation and capacity constraints enter as constraints into the optimization problem. We derived the Karush Kuhn Tucker (KKT) conditions to obtain a mixed complementarity problem (MCP) and solved it by using the PATH Solver in GAMS.

\section{Results}

Our main results are our predictions for invested quantities. It can be seen in table 1 that, given the cost and demand information we have, brown coal seems to be the dominant technology choice. If we rule out brown coal, which might be plausible as there is only a limited number of available sites, nuclear plants for the social planner, and nuclear and hard coal plants for the oligopolists become the technology of choice as can be seen in table 1 .

\section{Conclusions}

In this paper, we investigate inhowfar deregulated electricity markets can be expected to deliver optimal capacity investments. A purely analytical model cannot answer this question as, from the analytical side, as pointed out in our work and in von der Fehr and Harbord (1995), it is unclear whether the combination of a peak load pricing problem, an oligopolistic market structure and uncertainty will create under- or even overinvestment. The German electricity market provided us with a real world example for our numerical model. Building on Genc et al. (2007) we extend their framework further toward a more realistic representation of market states and technologies and develop a normative welfare-optimal benchmark. We came to the preliminary conclusion that there seems to be an underinvestment problem arising from the current market framework. Additionally, it seems as if the current market setup distorts investment choices away from flexible but capital intensive technologies. This conclusion looks 
even gloomier in the light of aging plants which have to be replaced and the nuclear phase out.

Further research will focus on a model which allows more conclusions about the long run development of capacities. Additionally, the use of different information structures would be interesting.

\section{References}

Genc, T. S., S. S. Reynolds, and S. Sen (2007). Dynamic Oligopolistic Games under Uncertainty: A Stochastic Programming Approach. Journal of Economic Dynamics and Control 31(1), 55-80.

Genc, T. S. and S. Sen (2008). An Analysis of Capacity and Price Trajectories for the Ontario Electricity Market Using Dynamic Nash equilibrium under Uncertainty. Energy Economics 30(1), 173-191.

von der Fehr, N. H. and D. Harbord (1995). Capacity Investment and Long-Run Efficiency in Market-Based Electricity Industries. In O. J. Olsen (Ed.), Competition in the Electricity Supply Industry: Experience from Europe and the United States. DJOF, Copenhagen. 